\title{
Survival in a cruel world: how Vibrio cholerae and Salmonella respond to an unwilling host
}

\author{
James Slauch, ${ }^{1}$ Ronald Taylor, ${ }^{2}$ and Stanley Maloy ${ }^{1,3}$ \\ ${ }^{1}$ Department of Microbiology, University of Illinois, Urbana, Illinois 61801 USA; ${ }^{2}$ Department of Microbiology, Dartmouth \\ Medical School, Hanover, New Hampshire 03755-3842 USA
}

\section{The stressful life of an enteric pathogen}

Enteric pathogens are exposed to a variety of harsh conditions: extremes of temperature and $\mathrm{pH}$, strong detergents and digestive enzymes, competition with an established community of microorganisms, and the host immune response. To survive, pathogens must express a variety of gene products that elude these onslaughts. Often these conditions act as signals to turn on or off the specific genes needed for adaptation to distinct microenvironments in the host.

The invading bacterium must be able to distinguish and adapt rapidly to differences in growth conditions between the outside environment and the host, and within different microenvironments in the host. Different microenvironments may have distinct temperatures, oxidation-reduction potentials, $\mathrm{pH}$, and concentrations of inorganic and organic nutrients. For example, before ingestion intestinal pathogens are often present in water at a low temperature, low osmotic strength, near-neutral $\mathrm{pH}$, and with a low concentration of organic nutrients. In contrast, once ingested by a mammalian host the pathogen must adapt to a higher temperature and higher osmotic strength. It is transiently exposed to low $\mathrm{pH}$ in the stomach, then within several hours after ingestion it passes to the intestine where it encounters a higher $\mathrm{pH}$, high concentrations of bile salts, anaerobiosis, and abundant organic nutrients. In addition, essentially all the iron in the host is tightly bound to proteins such as lactoferrin and transferrin, and it is actively sequestered by the host during infection. The ability to acquire iron under these conditions is essential for growth of most pathogens. If it survives these obstacles, the pathogen must then make intimate contact with appropriate host cells upon arriving in the lumen of the small bowel to stably colonize the intestine.

To survive this journey the pathogen must rapidly express a variety of gene products: iron chelators that allow it to scavenge the limiting iron, proteins that allow it to

${ }^{3}$ Corresponding author.

E-MAIL s-maloy@uiuc.edu; FAX (217) 244-6697. tolerate the low $\mathrm{pH}$ in the stomach, flagella and chemotaxis proteins that allow it to migrate to a suitable niche, adhesins that allow it to colonize the intestine, and toxins or invasins that allow it to elicit disease. Extracellular pathogens like Vibrio cholerae remain in the lumen of the intestine and produce toxins that cause the disease symptoms. Intracellular pathogens like Salmonella produce invasins that allow it to penetrate mucosal cells. Specific gene products must be turned on to adapt to each of these conditions, and simultaneously certain other gene products must be turned off. This finely tuned ability to turn "virulence genes" on and off in response to different conditions in the host is essential for pathogenesis.

\section{What is a virulence gene?}

Virulence factors are those properties of an organism that allow a pathogen to infect a host and cause a disease. Virulence depends upon numerous cell properties: both housekeeping functions required for growth and replication in the host, as well as functions specifically involved in pathogenesis. Thus, in a broad sense, any bacterial property that is required for entry, growth, or survival of a bacterium in the host may be considered a virulence factor. Virulence factors include properties of the bacterial cell surface that prevent killing by complement, adhesins that allow the bacterial cell to adhere to host cells, the ability to adapt to the acidic conditions in the host, and the ability to synthesize nutrients that are limiting in the host. For example, the aro $A$ gene product, which is required for aromatic amino acid biosynthesis, is essential for virulence of Salmonella presumably because aromatic amino acids are limiting in the intracellular environment (Stocker 1993), an insight that led to the development of a live, attenuated vaccine for Salmonella typhi.

Genes that encode virulence factors are often called virulence genes. When virulence genes are lost by mutation or segregation there is a considerable decrease in virulence. It has been estimated that $5 \%-10 \%$ of the genes in both $V$. cholerae and Salmonella typhimurium 
encode virulence factors. Many virulence genes are located on mobile genetic elements or in localized regions of the chromosome called "pathogenicity islands" (Groisman and Ochman 1996; Hacker et al. 1997). Typically, pathogenicity islands are present in the genome of pathogenic strains but absent from closely related nonpathogenic strains. The $\mathrm{G}+\mathrm{C}$ content of these regions is often very different from that of the rest of the genome, suggesting that they were inherited by horizontal gene transfer. They are often large regions that include multiple virulence genes. For example, the SPI I pathogenesis island in $S$. typhimurium is $\sim 40 \mathrm{~kb}$ and has a $\mathrm{G}+\mathrm{C}$ content of $40 \%-47 \%$ relative to an average $\mathrm{G}+\mathrm{C}$ content of $52 \%$.

\section{Regulation of virulence genes}

Not surprisingly, expression of virulence genes is regulated by a diversity of environmental signals (Mekalanos 1992). Furthermore, virulence genes are commonly regulated by multiple conditions, allowing different genes to respond to several different environmental signals individually or only when multiple signals occur at the same time (Tables 1 and 2).

Many virulence genes are regulated by global regulatory systems, that is, regulatory systems that control expression of multiple genes simultaneously. For example, a common signal for inducing virulence gene expression in V. cholerae and Salmonella is lack of iron availability, which stimulates derepression or activation of transcription by the global regulatory protein Fur.

Two-component signal transduction systems play a major role in regulation of virulence genes (Dziejman and Mekalanos 1995). These systems typically have a membrane-associated sensor module that responds to an extracellular signal and transmits the signal to an intracellular response regulator module, which carries out the adaptive response, usually by directly binding DNA and regulating gene expression (Parkinson 1995). Most often the sensor and receiver modules are distinct proteins. However, a variety of alternatives exist as well. For example, the toxR gene from $V$. cholerae encodes a single integral membrane protein that may function as both a sensor and transcriptional activator (DiRita 1995).

Because virulence relies on so many different genes and regulatory signals, mutations that compromise the ability of the pathogen to grow and replicate can affect virulence indirectly. Mutations that affect chromosome structure may fall into this category. DNA supercoiling has been reported to be a common feature in the regulation of many virulence genes (e.g., see Galan and Curtiss 1990; Parsot and Mekalanos 1992). This is not surprising because changes in DNA supercoiling affect many important processes, including DNA replication, recombination, and transcription. The extent of supercoiling may be modulated by a variety of environmental factors such as temperature, anaerobiosis, and osmolarity conditions, which are likely to be experienced by pathogenic bacteria during infection (for review, see Dorman 1991, 1996). Thus, it is possible that the level of supercoiling may be involved in coordinating expression of a variety of pleiotropic virulence genes. However, there remain many unanswered questions about the extent and mechanism of this regulation. One problem is that certain promoters are sensitive to supercoiling only when maintained in the correct DNA context, and transcription of adjacent genes can also affect the extent of local supercoiling. Thus, potential differences between local and global supercoiling may make it difficult to interpret results obtained when genes are cloned onto plasmids to study the effect of supercoiling. A second problem is that supercoiling increases or decreases the expression of many genes that have no known role in virulence; estimates suggest that $-50 \%$ of all genes are affected by supercoiling. Bacterial histone-like proteins may also affect virulence indirectly as a result of changes in chromosome structure (e.g., see Higgins et al. 1990). Even if supercoiling and histone-like proteins play a direct role in the global regulation of virulence genes, most virulence genes clearly are regulated by other systems as well.

\section{Identifying virulence genes}

A variety of approaches have been used to identify virulence genes (Maloy et al. 1996). The brute force approach is to isolate a large collection of null mutants and screen them individually for loss of virulence in tissue culture cells or animal models (Fields et al. 1986). Signature tag mutagenesis is an alternative approach for identifying mutants that fail to survive in the host. This approach involves mutagenesis with transposons carrying unique DNA sequence tags, permitting identification of rare

Table 1. Choreography of major virulence factors in V. cholerae

\begin{tabular}{|c|c|c|c|}
\hline $\begin{array}{l}\text { Anatomical site } \\
\text { in host }\end{array}$ & $\begin{array}{l}\text { Potential } \\
\text { environmental signals }\end{array}$ & Regulatory genes & Response \\
\hline \multirow[t]{2}{*}{ Stomach } & low $\mathrm{pH}$ & $h t p G$ & $\begin{array}{l}\text { stress response produces increased acid } \\
\text { tolerance }\end{array}$ \\
\hline & Fe starvation & fur & induction of iron regulated genes \\
\hline $\begin{array}{l}\text { Lumen of small } \\
\text { intestine }\end{array}$ & $\begin{array}{l}\mathrm{pH} \text {, osmolarity, } \\
\text { temperature, bile }\end{array}$ & $\begin{array}{l}\text { toxR/toxS, toxT, } \\
\quad \operatorname{crp}\end{array}$ & $\begin{array}{l}\text { motility, chemotaxis, and degradative } \\
\text { enzymes allow penetration of mucus gel }\end{array}$ \\
\hline $\begin{array}{l}\text { Epithelium of small } \\
\text { intestine }\end{array}$ & $\begin{array}{l}\mathrm{pH} \text {, osmolarity, } \\
\text { temperature, nutrients }\end{array}$ & $\begin{array}{l}\text { toxR/tox } S, \text { tox } T \\
\quad c r p, t c p I, \text { acf } B\end{array}$ & $\begin{array}{l}\text { induction of attachment }(t c p) \text { and other } \\
\text { colonization }(a c f) \text { factors; expression of } \\
\text { cholera toxin }\end{array}$ \\
\hline
\end{tabular}


Table 2. Choreography of major virulence factors in Salmonella

\begin{tabular}{|c|c|c|c|}
\hline $\begin{array}{l}\text { Anatomical site } \\
\text { in host }\end{array}$ & $\begin{array}{l}\text { Potential } \\
\text { environmental signals }\end{array}$ & Regulatory genes & Response \\
\hline \multirow[t]{2}{*}{ Stomach } & $\begin{array}{l}\text { Fe starvation } \\
\text { acid shock, log phase }\end{array}$ & $\begin{array}{l}\text { fur } \\
\text { fur }\end{array}$ & $\begin{array}{l}\text { induction of iron-regulated genes } \\
\text { transient acid tolerance response; induction of } \\
\text { at least } 50 \text { acid shock genes }(a s p)\end{array}$ \\
\hline & $\begin{array}{l}\text { low } \mathrm{pH} \text {, elevated } \\
\text { temperature, stationary } \\
\text { phase or nutrient } \\
\text { limitation }\end{array}$ & rpos & $\begin{array}{l}\text { sustained acid tolerance response; induction of } \\
\text { at least } 15 \text { asp }\end{array}$ \\
\hline $\begin{array}{l}\text { Lumen of small } \\
\text { intestine }\end{array}$ & $\begin{array}{l}\text { high } \mathrm{Mg}^{2+} \text {, low } \mathrm{O}_{2} \text {, high } \\
\text { osmolarity, contact with } \\
\text { host cells }\end{array}$ & $\operatorname{sir} A$, hil $A, \operatorname{inv} F$ & $\begin{array}{l}\text { activation of invasion genes of the type III } \\
\text { secretion system (sip) }\end{array}$ \\
\hline $\begin{array}{l}\text { Within } \\
\text { macrophages }\end{array}$ & low $\mathrm{Mg}^{2+}$ & phoPQ & $\begin{array}{l}\text { activation of pag genes and repression of prg } \\
\text { genes; resistance to toxic cationic peptides }\end{array}$ \\
\hline Spleen and liver & $\begin{array}{l}\text { stationary phase or nutrient } \\
\text { starvation; } \mathrm{O}_{2} \text {, short-chain } \\
\text { fatty acids }\end{array}$ & $r p o S, s p v R, c r p$ & $\begin{array}{l}\text { induction of } s p v A B C D \text {; required for persistance } \\
\text { and suppression of cell-mediated immunity }\end{array}$ \\
\hline
\end{tabular}

mutants that survive in vitro but fail to survive within the intact host from a large population of mutants by hybridization (Hensel et al. 1995; Shea et al. 1996). Based upon the prediction that many virulence factors are likely to affect gene products on the cell surface that interact with other cells or the environment, the mutant screening process can be simplified by using $\operatorname{Tn} p h o A$, a transposon that creates active reporter fusions only upon insertion into genes that encode membrane or secreted proteins (Taylor et al. 1987). Virulence genes also have been identified by simply screening for gene or operon fusions that are regulated by in vitro environmental signals likely to be encountered upon infection of a host (Taylor et al. 1987; Knapp and Mekalanos 1988; Maurelli and Sansonetti 1988; Peterson and Mekalanos 1988; J.F. Miller et al. 1989; Valdivia and Falkow 1996). A variety of in vivo expression technology (IVET) approaches use promoter fusions to reporter genes to identify genes that are specifically turned on during infection of a host (Mahan et al. 1993; Camilli and Mekalanos 1995; Heithoff et al. 1997).

Most of the approaches described above involve screening for loss-of-function mutations or for regulatory phenotypes. These approaches will identify both housekeeping genes required for virulence and genes directly involved in virulence. Two alternative approaches target functions directly involved in virulence. A number of virulence genes have been identified by transfer of a virulence phenotype to a surrogate nonpathogenic host. For example, the $V$. cholerae tox $R$ gene was discovered initially as a positive regulator required for expression of the cholera toxin gene (ctx) in Escherichia coli (Miller and Mekalanos 1984). In some cases it has been possible to directly select for gain-of-function mutations that enhance a virulence phenotype. For example, the $S$. typhimurium hil gene was identified initially as a mutation that enhances invasion into tissue culture cells in vitro (Lee and Falkow 1990; Lee et al. 1992).

\section{Two paradigms}

$V$. cholerae and Salmonella are paradigms of two different life styles of enteric pathogens (Fig. 1). V. cholerae is an extracellular pathogen, whereas Salmonella is an intracellular enteric pathogen. A brief review of some major features of $V$. cholerae and Salmonella pathogenesis and the regulation of virulence gene expression in response to the host environment follows. Many additional aspects of Salmonella pathogenesis can be found in Jones (1997) on host responses to Salmonella infection.

\section{Vibrio cholerae}

\section{Cholera}

Cholera is a life-threatening diarrheal disease that can rapidly attain acute epidemic proportions in essentially any part of the world where it is either endemic or newly introduced. Perhaps the major contributing factor to its rapid spread is inadequate sanitation measures with respect to water sources. The causative organism, V. cholerae, is a Gram-negative curved rod that is highly motile by means of a single polar flagellum. The $V$. cholerae strains that cause epidemic cholera have, until recently, been confined to the Ol serogroup that is composed of two biotypes, classical and El Tor, which are distinguished by hemagglutination properties, hemolysin production, and several biochemical tests. The classical biotype was responsible for essentially all cholera throughout the world until 1961, when the El Tor biotype largely displaced it. In late 1992, the first recorded non-Ol strain to be associated with epidemic cholera was identified in an epidemic that rapidly spread throughout the Indian subcontinent and into other regions of Asia. This strain, designated O139, appears to have arisen from the El Tor biotype, and after briefly replacing the O1 serogroup, $\mathrm{O} 139$ is currently coexistent with it throughout endemic 
Figure 1. Different life styles of $V$. cholerae and Salmonella. Both pathogens infect the host orally via contaminated food or water and then proceed to the small intestine (shown in pink). $V$. cholerae remains in the small intestine where it elicits toxin that causes the disease symptoms. In contrast, Salmonella crosses the intestinal barrier and can cause a systemic infection (shown in red). Salmonella penetrates the intestinal mucosa via specialized epithelial cells called $M$ cells /the smooth cells shown in the cartoon), that are involved in antigen processing and are associated with lymphoid follicles called Peyer's patches. In addition to $M$ cells, Peyer's patches contain macrophages and lymphocytes (the oval cells underlying the $M$ cells), and are surrounded by a network of lymphatic capillaries. The invading bacteria are engulfed by macrophages that are in close contact with the M cells. Macrophages then carry the bacteria via the lymphatic system to the spleen and liver, where the bacteria replicate. The bacteria subsequently enter the bloodstream causing septicemia. The bacteria also progress to the gall bladder and from there are shed into the intestine, where inflammation and ulceration of the Peyer's patches results in diarrhea.

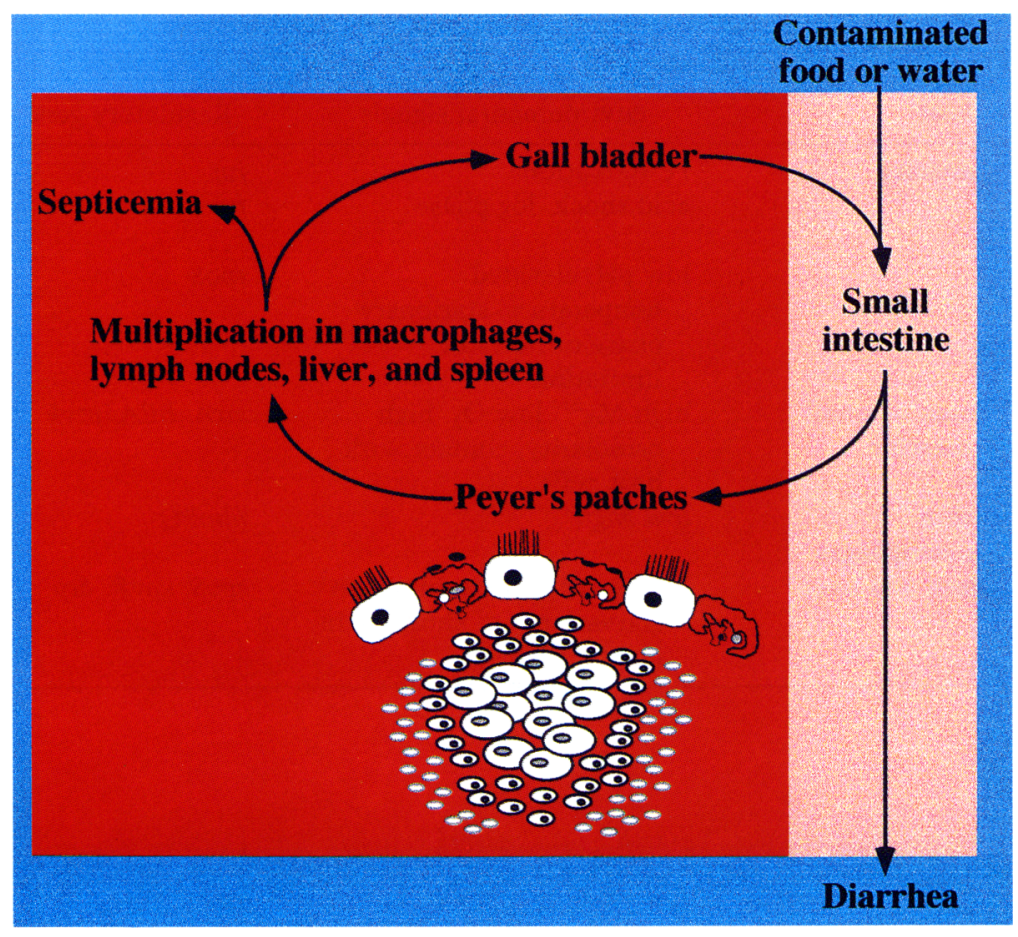

regions of the Asian subcontinent (Wachsmuth et al. 1994).

\section{Pathogenesis}

Cholera pathogenesis involves oral ingestion of $V$. cholerae from contaminated water or food, survival of the organism during passage through the gastric acid barrier of the stomach, colonization of the upper small intestine with concomitant toxin production, and ultimate dissemination in a watery diarrhea (Fig. 2). V. cholerae remains localized in microcolonies on the intestinal surface, without significant invasion to other sites of the host. Throughout the pathogenic process, the bacterium expresses a number of proven and potential virulence determinants that help it to reach, adhere to, and colonize the intestinal epithelial layer. The genes that encode many of these virulence factors, such as cholera toxin, are regulated by environmental stimuli such that they are expressed when the organism is in the host but not when it is in the outside environment. For a comprehensive review of cholera pathogenesis, see Kaper et al. (1995).

\section{Cholera toxin}

The main virulence determinant of $V$. cholerae is the secreted exotoxin (for review, see Betley et al. 1986; Kaper et al. 1994). This is suggested by the finding that even a small dose of toxin results in the full-blown diarrhea characteristic of the disease (Levine et al. 1979). In addition, mutants engineered specifically for loss of the toxin genes or their expression are attenuated greatly
(Herrington et al. 1988; Levine et al. 1988). The toxin is composed of one A subunit (molecular weight 27,215) and five identical B subunits (molecular weight 11,677) (Lospalluto and Finkelstein 1972; Gill 1976) encoded by the $\operatorname{ctx} A$ and $\operatorname{ctx} B$ genes, which are expressed as an operon (Mekalanos et al. 1983; Lockman et al. 1984). This operon is encoded by the CTX phage, which is present as a lysogen in all toxigenic isolates (Waldor and Mekalanos 1996). The B subunits are required for secretion of the toxin out of the bacterial cell (Hirst et al. 1984) and for its interaction with target cell surface ganglioside $\mathrm{GM}_{1}$ receptors (Cutrecasas 1973). The pentameric structure also likely participates in entry of the toxin A subunit into the target cell after which the A subunit is proteolytically nicked to become active (Mekalanos et al. 1979). It is the amino-terminal fragment of the A subunit, termed $\mathrm{A}_{1}$, that catalyzes the transfer of the ADP-ribose moiety from NAD to the regulatory $G$ protein, $G_{s \alpha}$, which then constitutively activates the mammalian adenylate cyclase leading to increased cAMP levels (Cassel and Pfeuffer 1978; Gill and Meren 1978). This, in turn, activates cAMP-dependent protein kinase $A$, which phosphorylates proteins involved in intestinal ion transport and produces the characteristic severe, watery diarrhea associated with cholera (Field 1980; Chang and Rao 1991; Kaper et al. 1994).

\section{Colonization factors}

$V$. cholerae efficiently delivers cholera toxin to host epithelial cell toxin receptors upon colonization of the small intestine. Genetic and immunological studies have identified a role for $V$. cholerae fimbriae in coloni- 


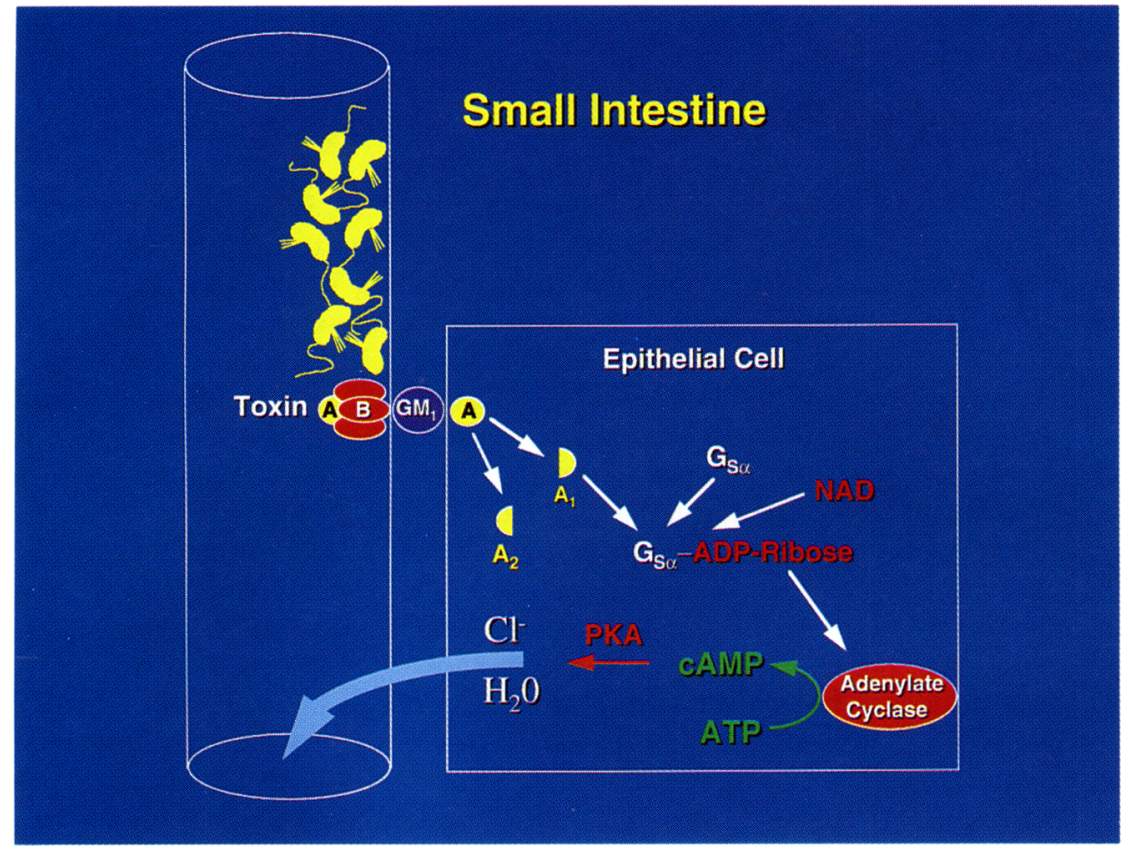

Figure 2. Processes involved in the pathogenesis of $V$. cholerae. The bacterium uses TCP pili to colonize the epithelial surface of the upper small intestine where it produces cholera toxin. The B subunit of the toxin then interacts with the target cell surface ganglioside $G M_{1}$ and the $A$ subunit enters the cell. Proteolytic cleavage of the A subunit generates the $A_{1}$ form that catalyzes the transfer of ADP-ribose from NAD to the $\alpha$ subunit of the regulatory protein $\mathrm{G}_{\mathrm{s}}$. This results in constitutive activation of the enzyme adenylate cyclase, which increases intracellular levels of cAMP. One of the targets of CAMP is the cAMP-dependent protein kinase A (PKA). Protein phosphorylation by PKA leads to an alteration of intestinal ion transport, resulting in severe diarrhea. zation. The $\mathrm{O} 1$ and $\mathrm{O} 139$ serotypes of $V$. cholerae can produce at least two fimbrial types under different growth conditions. One of these, composed of a $20.5-\mathrm{kD}$ subunit, is expressed under the same growth conditions that elicit the highest levels of toxin production and has thus been termed TCP, for toxin coregulated pilus (Taylor et al. 1987). The amino-terminal 25-amino-acid residue region of the mature subunit pilin protein, termed TcpA, is highly homologous to a group of pilin proteins called type 4 pilins (for review, see Strom and Lory 1993). Type 4 pili are implicated in the adhesion of several bacterial species that colonize or interact with mucosal surfaces. Using an infant mouse cholera model, the $\mathrm{LD}_{50}$ of tcp $A$ mutants was found to increase by $\sim 5$ logs.as compared with the wild-type parental strain. This is similar to the $\mathrm{LD}_{50}$ seen for $c t x$ toxin structural gene deletion mutants, demonstrating the central role of TcpA in $V$. cholerae pathogenesis. A role in colonization was established by competing the mutants with the wild-type strain in the infant mouse. In this model system, the tcpA mutants were found to be out-competed by 5-6 logs. Subsequent studies using additional defined $t c p A$ mutants, including in-frame deletions, have established the requirement of this organelle in the colonization of humans (Herrington et al. 1988; Rhine and Taylor 1994; Thelin and Taylor 1996). The precise molecular mechanisms by which TCP functions to promote colonization are not known, but appear to involve the ability to both adhere to and resist bactericidal mechanisms (Chiang et al. 1995).

Hemagglutination, or the agglutination of red blood cells, is an in vitro assay that is often used to study the potential of bacterial surface molecules to mediate interactions with host cells that might promote colonization. In addition to TCP, $V$. cholerae can produce other soluble and cell-associated hemagglutinins (Hanne and Finkelstein 1982). The MSHA (mannose-sensitive hemagglutinin) present on the surface of El Tor biotype strains has been associated with a pilus structure composed of a 16-kD pilin subunit (Jonson et al. 1991). Antibodies directed against this structure were shown to protect against challenge by strains of the El Tor biotype in the infant mouse cholera model, initially suggesting that MSHA might cooperate with TCP to promote intestinal colonization (Osek et al. 1994). However, genetic analysis using in-frame deletions of the pilin structural gene, $m s h A$, showed little influence of MSHA expression on colonization ability (Attridge et al. 1996; Thelin and Taylor 1996). A reexamination of the efficacy of antisera directed against TCP and MSHA to protect against challenge by El Tor biotype strains has shown that significant protection is provided only by anti-TCP antisera (Attridge et al. 1996). Thus, a colonization role for MSHA is not apparent. Because El Tor strains are known to exhibit enhanced environmental survival in comparison to classical biotype strains, it is perhaps possible that MSHA contributes to colonization of some other ecological niche that is critical for this ability.

Yet another set of genes that appear to have a role in colonization are termed the acf laccessory colonization factor| genes. These genes were identified as $\operatorname{Tn} p h o A$ fusions that expressed alkaline phosphatase in response to various growth conditions in a manner similar to that of the toxin and TCP genes (Peterson and Mekalanos 1988). Mutations in acf genes exhibit a 10 -fold colonization defect in the infant mouse cholera model. The nature of this defect has yet to be discerned but may be attributable to a defect in a regulatory response rather than a direct interaction with the host (Everiss et al. 1994b). The acf genes are clustered together adjacent to 
the $t c p$ genes and are transcribed from three different promoters, one of which is involved in expression of the tcp operon (Everiss et al. 1994a; Brown and Taylor 1995). The $t c p$ and $a c f$ genes are located on a large pathogenicity island termed the TCP-ACF element (Kovach et al. 1996).

In addition to specific attachment organelles, motility also plays a role in the ability of the organism to colonize. Both nonmotile and hypermotile mutants are generally less virulent in several animal models (Richardson 1991; Gardel and Mekalanos 1996). Potential vaccine strains that have been determined to be less reactogenic are also less motile. Thus there appears to be a correlation between motility and the ability to cause inflammation and diarrhea simply via heavy colonization of the small intestine (Mekalanos and Sadoff 1994). Interestingly, expression of genes required for motility has been shown to be inversely regulated with respect to cholera toxin and TCP gene expression. For example, tox $R$ mutants (see below), which are no longer capable of expressing TCP or toxin, are hypermotile. This effect may be attributable to loss of expression of the $t c p I$ and $a c f B$ genes, which are located on the TCP-ACF pathogenicity island and require ToxR and ToxT for their expression. Both $t c p I$ and $a c f B$ encode proteins that share homology with the signaling domain of methyl-accepting chemotaxis proteins, and mutation of either one results in a hypermotile phenotype (Everiss et al. 1994b; Harkey et al. 1994). These results suggest a regulatory network whereby the bacteria use motility to reach a potential site for colonization and, once there, shut off motility and express the genes required for colonization and toxigenicity (Gardel and Mekalanos 1996).

\section{Regulation of virulence gene expression}

The regulatory gene tox $R$ was first identified by virtue of its ability to activate a $c t x-l a c Z$ transcriptional fusion in E. coli (Miller and Mekalanos 1984). Sequence analysis of the toxR gene suggested a protein product of $32.5 \mathrm{kD}$ with a single transmembrane domain and a region in the amino-terminal half of the protein sharing extensive homology with the DNA-binding portion of several transcriptional activators involved in bacterial transmembrane regulatory systems (so-called two-component systems) (Miller et al. 1987). The use of $p h o A$ fusions helped to demonstrate that ToxR spans the inner membrane of the bacterial cell, with the amino terminus in the cytoplasm and the carboxy terminus in the periplasm. Membrane extracts from ToxR-expressing cells have been shown to bind the $c t x$ promoter region by gel-shift assays (Miller et al. 1987). ToxR does not act independently. The product of a second gene, tox $S$, which is located in the same transcriptional unit as tox $R$, modulates its action (DiRita and Mekalanos 1991). The predicted secondary structure of ToxS suggests that it is also an integral cytoplasmic membrane protein, but with the bulk of its structure on the periplasmic side. The phenotype exhibited by toxS deletion mutations is a decrease in the expression of ToxR-regulated genes under some growth conditions. Most evidence at this time suggests that the role of the ToxS protein may be to stabilize ToxR in a conformation capable of transcriptional activation, perhaps as a dimer (Miller et al. 1987; Kolmar et al. 1995; Ottemann and Mekalanos 1996).

The ToxR and ToxS proteins are required for expression of numerous genes in addition to the $\operatorname{ct} x A B$ operon (DiRita 1992). The genes encoding TCP, ACF, the OmpU outer membrane protein, and several other potential virulence factors are also under ToxR control (Peterson and Mekalanos 1988). This group of coordinately regulated genes is referred to as the ToxR virulence regulon. Not all genes within the ToxR virulence regulon are directly activated by ToxR. In fact, expression of most of the ToxR regulon genes is controlled indirectly through a second regulatory protein called ToxT (DiRita et al. 1991). Cloned toxT activates expression of these genes in E. coli, and if expression of toxT is controlled from a heterologous promoter in $V$. cholerae, it overrides ToxR control of the regulon. These results and others have led to a cascade model in which ToxR activates expression of toxT, which, in turn, positively regulates most of the genes of the ToxR regulon (DiRita et al. 1991, 1996). ToxT is a cytoplasmic protein and belongs to the AraC family of transcriptional regulators (Higgins et al. 1992; Ogierman and Manning 1992; Gallegos et al. 1993). The toxT gene actually lies within the tcp operon (Higgins et al. 1992; Kaufman et al. 1993) and is cotranscribed with the $t c p$ genes. Further studies suggest that once toxT expression is activated by ToxR, and perhaps additional factors, its expression is maintained by an autoregulatory mechanism attributable to the ability of ToxT to activate transcription of the $t c p$ operon that includes the toxT gene (Higgins and DiRita 1994; Brown and Taylor 1995).

The precise roles of ToxR and ToxT in regulating the expression of the cholera toxin genes are not yet understood. When either toxR or toxT alone are present in $E$. coli, either gene is capable of activating $\operatorname{ctx} A B$ expression. However, the recent finding that a toxT mutation in $V$. cholerae results in complete loss of $c t x$ expression (Champion et al. 1997) brings the exact role of ToxR at the ctx promoter in $V$. cholerae into question. For example, it is possible that ToxR does not directly activate ctx expression, or if it does, it may act in concert with ToxT or another factor that requires ToxT for expression. The latter possibility would imply that a gene encoding a ToxT homolog, or the missing factor, is present in E. coli and can be activated by ToxR.

One aspect of the ToxR regulon that has remained obscure is the mechanism by which environmental conditions promote ToxR regulon gene expression in vivo, and repress expression outside of a suitable host. For example, factors such as $\mathrm{pH}$, temperature, osmolarity, and amino acids present in the growth medium, as well as the growth phase, have been shown to influence the expression of the ToxR regulon under laboratory conditions (Miller and Mekalanos 1984). The effect of temperature can be explained at least partially by the finding that the heat shock gene $h t p G$ is expressed from a pro- 
moter that overlaps the tox $R$ promoter and is transcribed in the opposite direction. Under conditions of elevated temperature or other stress, such as the low $\mathrm{pH}$ of the stomach, activation of $h t p G$ expression may decrease the expression of toxR and the ToxR virulence regulon genes (Parsot and Mekalanos 1990). Given the complexity of the in vivo environment, it seems unlikely that all of the conditions that induce the expression of the ToxR regulon in vitro mimic the situation in the intestine.

Despite intensive investigation, it has not yet been demonstrated that the ToxRS system itself is capable of sensing environmental stimuli and controlling gene expression accordingly. To investigate whether additional proteins might be required for the process of sensing external stimuli and converting it into regulatory information, a chromosomal ctx-lac Z reporter gene in V. cholerae was used in combination with transposon mutagenesis to identify genes that influence ToxR regulon gene expression under various environmental conditions (Skorupski and Taylor 1997). Using this system, mutations in the cAMP-CRP system of $V$. cholerae were found to derepress $c t x$ and $t c p$ gene expression under certain growth conditions normally repressive for ToxR regulon gene expression. A potential cAMP-CRP binding site identified previously in the $t c p$ promoter (Thomas et al. 1995) might be used by this complex to repress expression of the $t c p$ operon and the regulatory gene toxT under various environmental conditions. This would provide a mechanism for input into the regulon at the ToxT portion of the cascade without directly influencing the regulation provided by ToxR.

Environmental regulation of virulence genes that are not part of the ToxR regulon is also well documented. One such regulon that has been characterized responds to iron concentration. Identification of iron-regulated genes was accomplished by identifying phoA fusions induced under low iron conditions (Goldberg et al. 1990). These studies identified genes termed irg for iron-regulated genes and viu for vibriobactin uptake. The common repressor for these genes is the Fur protein, which is homologous to that of $E$. coli (Litwin and Calderwood 1994). Some of these genes, for example, viuA, have a role in a siderophore iron uptake system that is crucial for survival of the bacteria in the iron-limiting conditions of the host (Butterton et al. 1992).

Other iron-regulated systems are required for full virulence, but their precise roles have yet to be defined. One of these is hemolysin production, a characteristic of most El Tor biotype isolates. Hemolysin is encoded by the hly $A$ gene, the expression of which requires the HlyU protein (Stoebner and Payne 1988). Both hlyA and hly $U$ mutants exhibit an increased $\mathrm{LD}_{50}$ in the infant mouse cholera model. The role of hemolysin in interaction of $V$. cholerae with the host is not yet understood, but it is possible that lysis of host cells provides a source of iron for the bacteria. The hly $U$ mutant, but not the hly $A$ mutant, is slightly defective in colonization competition assays, suggesting the possibility that the HlyU protein regulates factors in addition to hemolysin expression that might be critical for intestinal colonization
(Williams et al. 1993). It remains to be determined how iron regulation of hemolysin production occurs.

\section{Horizontal gene transfer and V. cholerae pathogenesis}

The virulence potential of $V$. cholerae involves a fascinating interplay between genes and regulatory elements encoded within the ancestral chromosome and on acquired pathogenesis islands and lysogenic phage. The toxR gene, present in the chromosome of both toxigenic and nontoxigenic Vibrio species, activates the expression of certain outer membrane protein genes (e.g., omp $U$ in $V$. cholerael, the $\operatorname{ctx} A B$ operon encoded by the lysogenic CTX phage, and the regulatory toxT gene encoded within the TCP-ACF pathogenesis island. In turn, ToxT is required for expression of genes encoded within the TCP-ACF element, such as the $t c p$ and acf genes, as well as the ctx operon of the phage, but does not regulate ompU expression. That TCP serves as the CTX phage receptor suggests that in the evolution of the toxigenic strains the TCP-ACF element had to be acquired before the phage could infect and lysogenize the strain. In fact, transfer of CTX phage between V. cholerae strains in the intestine has been demonstrated with the infant mouse cholera model (Waldor and Mekalanos 1996). Thus, the intestine provides an environment in which the CTX phage uses the proteins encoded by the TCP-ACF element both to facilitate infection of a susceptible host strain and to regulate the production of cholera toxin upon lysogen formation. This combination apparently has led to the evolution of strains with superior ability to colonize and survive within the human host.

\section{Salmonella}

In contrast to the extracellular life style of $V$. cholerae, Salmonella is an intracellular pathogen. The intracellular life style is substantially more complex, requiring the elucidation of numerous virulence factors, including regulatory mechanisms that respond to multiple environmental parameters and thus distinguish each unique niche in the host.

\section{Salmonellosis}

The incidence of nontyphoid Salmonella gastroenteritis and enteric fever in the United States has increased significantly in the last decade with Salmonella enterica serovariant Typhimurium (S. typhimurium) continuing to be a significant serotype involved in disease (Centers for Disease Control 1996). Total estimates of salmonellosis in the United States range from 0.8 to 3.7 million cases per year (Chalker and Blaser 1988). Infection of humans by nontyphoid Salmonella usually results in gastroenteritis. Although this is often a self-limiting disease marked by abdominal symptoms, the infection can be more severe, resulting in bacteremia, fever, or other complications (Miller et al. 1995). Other Salmonella serovars such as $S$. typhi characteristically produce the se- 
vere systemic disease called typhoid fever (Keusch and Thea 1989).

S. typhimurium infection of a mouse serves as a wellestablished model of systemic salmonellosis as well as a general model system to study host-pathogen interaction at the molecular level. $S$. typhimurium infection in mice mimics the systemic disease caused by $S$. typhi in humans. In a mouse $S$. typhimurium survives and propagates in a wide variety of tissues, circumventing or taking advantage of several aspects of the host immune system. The genes whose products are designed to cope with these various hostile environments are regulated tightly such that they are expressed only at the appropriate time and place in the host.

\section{Acid tolerance}

Infection by Salmonella is usually by the oral route as a result of ingesting contaminated food, water, or milk (Miller et al. 1995). Upon ingestion, the bacteria must initially survive the acid environment of the stomach. Subsequently, the bacteria must survive the acidic environment within the phagocytic vesicle of the macrophage. Several mechanisms of coping with these acidic conditions have been uncovered in $S$. typhimurium by studying acid survival in vitro (for review, see Foster 1995).

The log-phase acid tolerance response (ATR) is a $\mathrm{pH}$ inducible system that involves the synthesis of at least 50 so-called acid shock proteins (ASPs), several of which have been implicated in survival at $\mathrm{pH}$ 3.3. This system can be broken down into a transient response and a sustained response. Several of the transient response proteins apparently are activated by the iron regulatory protein Fur. Hall and Foster (1996) reported the isolation of a fur mutation that abolishes repression of iron-regulated genes but does not affect the activation of asp gene expression in response to low $\mathrm{pH}$, indicating that the requirement for Fur is independent from its regulatory role in iron scavenging. Furthermore, low iron does not induce all of the Fur-dependent ASP proteins. Some evidence suggests that in addition to functioning as a repressor, Fur can also act directly as an activator (Gruer and Guest 1994; Hall and Foster 1996). The multiple functional roles of Fur illustrate the complexity of the regulatory network that controls expression of virulence genes.

The sustained ATR response is largely dependent on the stationary phase sigma factor RpoS. However, overproduction of RpoS is insufficient to induce the sustained response. Indeed, many of the ASPs are also regulated by other environmental factors such as heat shock, phosphate, nitrogen, and carbon starvation, and the presence or absence of oxygen. Two other acid survival systems are induced in stationary phase. The first is induced in a $\mathrm{pH}$-independent fashion and is dependent on RpoS. The second stationary phase system is a slow responding, low $\mathrm{pH}$-inducible system involving induction of at least 15 proteins.

The role of these various systems in pathogenesis has been tested only recently. Mutations that conferred acid sensitivity to strain LT2, including mutations in fur and atp, were transduced into virulent $S$. typhimurium strains, and the resulting mutants were tested in the animal model as well as various in vitro tests of virulence (Garcia-del Portillo et al. 1993). The fur mutants show an -2-log increase in the oral $\mathrm{LD}_{50}$, but are not apparently affected systemically. Interestingly, the fur defect could be rescued partially by buffering the stomach, suggesting that at least part of the defect of this relatively pleiotropic mutation is directly dependent on stomach acid (Garcia-del Portillo et al. 1993). The atp gene encodes the $\mathrm{Mg}^{2+}$-dependent proton-translocating ATPase. Given the metabolic role of this enzyme, it is not surprising that strains containing mutations in the atp gene were extremely attenuated both orally and systemically. Riesenberg-Wilmes et al. (1996) tested the role of several additional atr genes in virulence. With the exception of strains containing polA mutations (atrC), single atr mutations showed only subtle effects on virulence. Furthermore, in some of the virulent strain backgrounds, the mutations did not confer acid sensitivity in vitro. Although these authors did not buffer the stomach acid prior to oral inoculation, the bacteria were administered in buffered saline. Therefore, it is not clear whether the sensitivity to stomach acid has been tested rigorously for these mutants.

\section{Invasion}

Organisms that survive the gastric barrier colonize the small intestine. The bacteria preferentially invade and colonize the Peyer's patches in the distal ileum (for review, see Jones 1997). Peyer's patches are specialized lymphoid tissue designed to sample intestinal antigens and lead to an immune response that preferentially involves the production of IgA. Overlaying the Peyer's patches are specialized epithelial cells ( $M$ cells) that are responsible for uptake of luminal antigens. These $M$ cells are the most likely route of invasion by $S$. typhimurium. However, S. typhimurium is also capable of inducing normally nonphagocytic epithelial cells to internalize bacteria. An understanding of the molecular mechanisms that allow this invasion has been obtained through the study of this process in vitro, by use of epithelial cells in tissue culture. Invasion of epithelial cells, a process termed bacterial-mediated endocytosis, is associated with the formation of large membrane ruffles and rearrangement of the eukaryotic cell cytoskeleton similar to rearrangements induced by treatment of epithelial cells with certain growth factors (Jones 1997). Genetic analysis shows invasion to be a two-step process of attachment and subsequent entry.

Many of the genes required for invasion are located in a contiguous $40-\mathrm{kb}$ cluster located at $63 \mathrm{~min}$ on the $S$. typhimurium chromosome, an island of Salmonella pathogenesis genes called SPII (for review, see Galan 1996). Most of the genes in this cluster encode a type III secretion system required to export the so-called Sip proteins to the cell surface of $S$. typhimurium. Another type 
III secretion system is encoded on a second pathogenesis island, called SPI2, located at $31 \mathrm{~min}$ on the S. typhimurium chromosome (Shea et al. 1996). This second type III secretion system seems to play an auxiliary role in virulence (Hensel et al. 1997).

\section{Regulation of virulence gene expression}

Expression of many, if not all, of the genes required for invasion is regulated in response to the environment such that invasion is induced only in low oxygen, high osmolarity, and alkaline $\mathrm{pH}$. Invasion is also repressed by the two-component regulatory system PhoPQ (Fig. 3). All of these conditions have to occur simultaneously to obtain significant gene expression. Bajaj et al. (1996) have shown recently that all of these environmental signals are mediated through the controlled expression of HilA, a transcriptional activator of the OmpR/ToxR family that is encoded in SPI1. Although there is some evidence that HilA acts directly on some promoters in the invasion locus, it also regulates InvF, a member of the AraC family of transcriptional regulatory proteins, which is responsible for activation of a subset of invasion genes.

How is HilA regulated? Johnston et al. (1996) isolated an insertion mutation that affected the expression of the prgHIJK operon in the invasion locus. The mutant gene, designated sirA, encodes a putative protein in the fixl family of two-component response regulators. Mutations in sirA affect transcription of hilA. Thus, the environmental regulation of the inv locus represents a cas- cade of regulatory proteins: SirA activates HilA, which acts directly on some invasion gene promoters and also regulates InvF, responsible for activation of a subset of invasion genes. It is not clear where PhoP acts in this regulatory cascade. Johnston et al. (1996) identified plasmids that complement the sir $A$ mutation. In addition to cloning $\operatorname{sir} A$, they isolated two additional plasmids that suppressed the $\operatorname{sir} A$ phenotype. These additional loci were designated $\operatorname{sir} B$ and $\operatorname{sir} C$. Partial DNA sequence analysis suggests that $\operatorname{sir} C$ is located in a region of SPIl uncharacterized previously. It is not clear how the sir $B$ and sirC loci fit into the regulatory circuit.

There is growing evidence that secretion of the invasion proteins via the type III secretion system is activated upon contact with host cells. The interaction of $S$. typhimurium with tissue culture cells results in the assembly of transient surface structures called invasasomes and the secretion of inv proteins. Presumably, these events are related to one another. De novo protein synthesis is not required for these events. How this system detects the host cell is not yet clear (for review, see Galan 1996).

\section{Systemic infection}

Following invasion, S. typhimurium enters cells of the reticulo-endothelial system and is spread systemically to target organs, particularly the spleen, liver, and bone marrow (Miller et al. 1995). An important aspect of this spread is the ability of $S$. typhimurium to survive in mac-

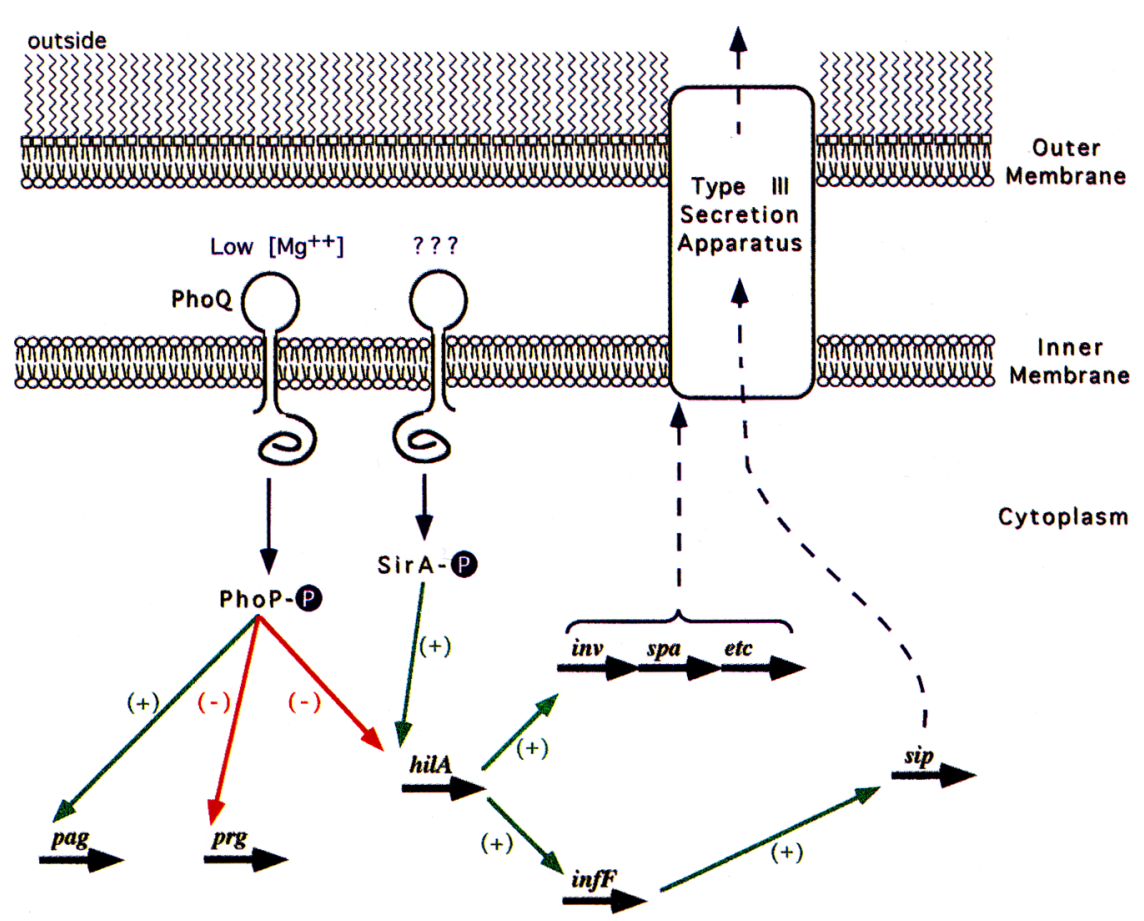

Figure 3. A complex regulatory cascade is required for Salmonella to invade host cells. Only the major Salmonella regulatory factors are shown. Upon interaction of the bacterium with the host epithelial cell, environmental signals promote the phosphorylation of SirA (SirA-P), which then induces expression of the hilA gene. HilA induces expression of the infF gene and at least 17 additional genes (inv, spa, etc.) that encode the components of the type III secretion apparatus. InfF induces expression of sip genes. The Sip proteins are exported across the inner and outer membrane via a type III secretion system (dashed line) and presumably transmit a signal to the eukaryotic cell that facilitates invasion. After crossing the epithelial barrier, Salmonella is engulfed by macrophages. PhoQ senses the low $\mathrm{Mg}^{2+}$ concentrations in the phagolysosome and phosphorylates PhoP (PhoP-P), which then positively regulates a subset of virulence genes (designated pag genes) and negatively regulates another subset of virulence genes (designated prg genes). The hilA gene is negatively regulated by PhoP-

$\mathrm{P}$, thus turning off the expression of the invasion genes. Green arrows $(+)$ indicate stimulation of transcription; red arrows $(-)$ indicate inhibition of transcription, although in some cases the transcriptional regulation may be indirect. Blue arrows (solid and broken) indicate steps responsible for phosphorylation, assembly of the invasasome, and protein secretion. 
rophages. Within macrophages, $S$. typhimurium cells are found in phagolysosomes in which the bacteria are subjected to both oxygen-dependent and oxygen-independent killing mechanisms. S. typhimurium apparently has the ability to both prevent the induction of these killing mechanisms and survive them once induced (Alpuche Aranda et al. 1992; Abshire and Neidhardt 1993). When $S$. typhimurium enters macrophages in culture $>40$ bacterial proteins are induced (Abshire and Neidhardt 1993).

The role of $p h o P$ in virulence was discovered by Fields et al. (1986) in a screen of mutations that prevent growth in macrophages. The phoPQ gene products encode a twocomponent regulatory system that is essential for macrophage survival (Groisman et al. 1989; S.I. Miller et al. 1989; for review, see Groisman and Heffron 1995). The PhoPQ regulon is activated in the phagolysosome (Alpuche Aranda et al. 1992), and regulatory mutants are defective in macrophage survival in culture (Miller et al. 1989; Miller and Mekalanos 1990). These mutants are sensitive to low $\mathrm{pH}$ in vitro, although the acid tolerance response is still induced (Foster 1995). Mutations in phoP also confer sensitivity to defensins, a family of small cationic, microbicidal peptides found in macrophages as well as the small intestine (Groisman and Heffron 1995). Garcia Vescovi et al. (1996) have provided evidence that $\mathrm{PhoQ}$ senses either $\mathrm{Mg}^{2+}$ or $\mathrm{Ca}^{2+}$ and activates PhoP (presumably via phosphorylation) under low $\mathrm{Mg}^{2+}$ concentrations.

A number of genes under the control of PhoPQ have been identified. Mutations in some of the genes regulated by PhoPQ show virulence defects (Groisman and Heffron 1995). PhoPQ activates some genes (termed pag) and represses other genes (termed prg) (S.I. Miller et al. 1989; Miller and Mekalanos 1990). Both constitutive and null mutants of $p h o P$ are attenuated (Miller and Mekalanos 1990), indicating that not only must certain genes be expressed to enable the bacteria to survive and propagate in the host, but these genes must be regulated such that they are expressed only at the appropriate time and the appropriate place in the host. As mentioned above, PhoPQ also represses hilA expression (directly or indirectly) and thus down-regulates expression of the inv genes.

Nontyphoid Salmonella serovars carry a large $150-100$ $\mathrm{kb}$ ) plasmid that plays a role in virulence. Strains cured of this virulence plasmid are attenuated (Gulig 1990). Virulence properties attributed to the plasmids include the ability to spread after colonization and invasion of the intestine, enhancement of the ability to grow in the spleen, and a general suppression of cell-mediated responses to Salmonella antigens (Hoertt et al. 1989; Gulig 1990). The overall structures of the plasmids from different Salmonella strains vary and several regions of various plasmids have been identified as being important for virulence. However, a highly conserved $7.8 \mathrm{-kb}$ region in the $S$. typhimurium plasmid is sufficient to complement a plasmid-cured strain for essentially full virulence after oral infection (Gulig et al. 1992). This locus, termed $s p v$ (Salmonella plasmid virulence), encodes five genes in- cluding a regulatory gene, $s p v R$, which is a member of the LysR family and acts as a positive regulator of the spvABCD and its own synthesis (for review, see Guiney et al. 1995). Although the specific functions of the $s p v$ genes are unknown, this locus is required for sustained growth in the liver and spleen. The $s p v$ operon is induced in stationary phase or by nutrient limitation in vitro, and rapidly induced in both epithelial cells and macrophages. Expression of the $s p v$ operon is dependent on RpoS, but induction of the $s p v$ operon is repressed by the cAMPCRP complex (O'Byrne and Dorman 1994) and under anaerobic conditions. The current model for $s p v$ regulation is as follows: In exponential phase, SpvR is produced at a low level. As the growth rate slows, RpoS levels increase and SpvR activates $\sigma^{\mathrm{s}}$ RNA polymerase to transcribe $s p v R$ and the $s p v A B C D$ operon (Chen et al. 1995). However, the regulation of $s p v$ may be much more complex than this model implies. Low iron, high temperature, and low $\mathrm{pH}$ are also reported to induce spvABCD expression in Salmonella dublin (Valone et al. 1993). In addition, the $S$. dublin operon is induced by short-chain fatty acids in both exponential and stationary phase (El-Gedaily et al. 1997). Short-chain fatty-acid induction in exponential phase is dependent on RpoS, but significant induction takes place in stationary phase in the absence of the sigma factor. The induction is dependent on SpvR in both instances.

The mviA gene, which encodes another putative twocomponent response regulator, was identified as a locus that affected the virulence of $S$. typhimurium strain LT2. As strain LT2 has been maintained in the laboratory for many decades it has become relatively avirulent. Derivatives of strain LT2 with a mutation in the mviA gene are more virulent then isogenic $m v i A^{+}$strains, but a significant difference between the two alleles is seen only in strains of mice that have an ity ${ }^{s}$ mutation that enhances their susceptibility to Salmonella infections (Benjamin et al. 1991). MviA (and the E. coli homolog RssB or SpvE) controls the stability of RpoS, most likely by affecting the access of RpoS to the ClpX protease (Bearson et al. 1996; Muffler et al. 1996; Pratt and Silhavy 1996). The stability of RpoS is increased in high osmolarity, and this regulation is absent in the $E$. coli rss $B$ mutant. But whether osmolarity is a primary signal for MviA/RssB is unclear. A corresponding sensor protein for MviA/RssB has not been identified. A major virulence defect of strain LT2 is decreased expression of RpoS because of a rare start codon, UUG (Lee et al. 1995). The mviA mutation apparently stabilizes RpoS leading to increased levels of RpoS in the LT2 background. All of the virulent $S$. typhimurium strains checked by Benjamin et al. (1991) were $\mathrm{mviA}^{+}$.

OmpR and EnvZ comprise a two-component system that regulates the major outer membrane porins, OmpF and $\mathrm{OmpC}$, in response to the media osmolarity (for review, see Slauch and Silhavy 1996). EnvZ is an inner membrane sensor component that communicates environmental information to OmpR, a transcriptional regulator. Dorman et al. (1989) showed that insertion mutations in ompR dramatically attenuated virulence of $S$. 
typhimurium in a mouse model. Insertion mutations in ompF or ompC did not affect virulence. Subsequently, it was shown that strains containing mutations in both $o m p F$ and ompC were attenuated (Chatfield et al. 1991), which may simply be attributable to a general loss of diffusion across the outer membrane (Slauch and Silhavy 1995). However, the fact that $\operatorname{ompR}$ mutants are more attenuated than the ompF, ompC double mutants suggests that the regulator has a further role in virulence (Chatfield et al. 1991). Recently, several laboratories have demonstrated that $S$. typhimurium is cytotoxic for macrophages (Chen et al. 1996; Lindgren et al. 1996; Monack et al. 1996). Lindgren et al. (1996) showed that four independent mutants abolished this cytotoxicity, but still survived in macrophages all mapped to the ompRenvZ operon. They hypothesize that OmpR and EnvZ are required to activate or repress a gene required for the cytotoxic effect.

\section{Summary}

$V$. cholerae and Salmonella are paradigms of extracellular and intracellular enteric pathogens. S. typhimurium has been a workhorse of bacterial genetics for many years, providing a sophisticated set of genetic tools for construction and analysis of mutants. In contrast, $V$. cholerae only recently has become amenable to genetic analysis. Despite this disparity in genetic tools, the basis of $V$. cholerae virulence is better understood than $S$. typhimurium virulence because of the additional mechanistic complexity necessary for intracellular pathogenesis.

Both $V$. cholerae and Salmonella have evolved an exquisitely refined molecular choreography to express the right genes at the right time and in the right place to facilitate infection of the host. Although many virulence factors have been identified in both these enteric pathogens, there remain gaping holes in our knowledge of both the virulence genes and regulatory genes required for pathogenesis. Understanding the regulation of virulence genes may provide insight into conditions a pathogen encounters upon infection, thus providing an approach for identifying other virulence genes. Once the regulatory signals are identified, dissecting the details of the regulatory mechanism may give further clues to the mechanism of virulence and may identify new targets for antimicrobial agents.

It is noteworthy that despite the wealth of elegant research on $V$. cholerae and Salmonella, we are still far from fully understanding their virulence from either the pathogen or host perspective. Moreover, these are just two examples from a countless number and variety of important bacterial pathogens.

\section{Acknowledgments}

Because of the profusion of publications on bacterial pathogenesis and limited length of this review, we were unable to reference all of the significant publications in this field. We apologize to anyone we failed to cite. We thank Karen Skorupski and
Tom Zahrt for helpful comments on the manuscript and Teresa Rebello for the Peyer's patch cartoon in Figure 1. J.S. is supported by U.S. Public Health Service grant AI-37530, American Heart Association Illinois Affiliate grant 96-GB-01, and a Junior Faculty Research Award from the American Cancer Society; R.T. is supported by U.S. Public Health Service grants AI-25096 and AI-39654; S.M. is supported by U.S. Public Health Service grant GM-34715.

\section{References}

Abshire, K.Z. and F.C. Neidhardt. 1993. Analysis of proteins synthesized by Salmonella typhimurium during growth within a host macrophage. J. Bacteriol. 175: 3734-3743.

Alpuche Aranda, C., J. Swanson, W. Loomis, and S.I. Miller. 1992. Salmonella typhimurium activates virulence gene transcription within acidified macrophage phagosomes. Proc. Natl. Acad. Sci. 89: 10079-10083.

Attridge, S.R., P.A. Manning, J. Holmgren, and G. Jonson. 1996. Relative significance of mannose-sensitive hemagglutinin and toxin-coregulated pili in colonization of infant mice by Vibrio cholerae El Tor. Infect. Immun. 64: 3369-3373.

Bajaj, V., R.L. Lucas, C. Hwang, and C.A. Lee. 1996. Co-ordinate regulation of Salmonella typhimurium invasion genes by environmental and regulatory factors is mediated by control of hilA expression. Mol. Microbiol. 22: 703-714.

Bearson, S., W. Benjamin, Jr., W. Swords, and J. Foster. 1996. Acid shock induction of RpoS is mediated by the mouse virulence gene mviA of Salmonella typhimurium. J. Bacteriol. 178: 2572-2579.

Benjamin, W.H., Jr., J. Yother, P. Hall, and D.E. Briles. 1991. The Salmonella typhimurium locus mviA regulates virulence in Ity $^{\mathrm{s}}$ but not Ity ${ }^{\mathrm{r}}$ mice: Functional mviA results in avirulence; mutant (nonfunctional) mviA results in virulence. $J$. Exp. Med. 174: 1073-1083.

Betley, M.J., V.L. Miller, and J.J. Mekalanos. 1986. Genetics of bacterial enterotoxins. Annu. Rev. Microbiol. 40: 577-605.

Brown, R.C. and R.K. Taylor. 1995. Organization of $t c p$, acf, and toxT genes within a ToxT-dependent operon. Mol. Microbiol. 16: 425-439.

Butterton, J.R., J.A. Stoebner, S.M. Payne, and S.B. Calderwood. 1992. Cloning, sequencing, and transcriptional regulation of $\operatorname{viu} A$, the gene encoding the ferric vibriobactin receptor of Vibrio cholerae. I. Bacteriol. 174: 3729-3738.

Camilli, A. and J. Mekalanos. 1995. Use of recombinase gene fusions to identify Vibrio cholerae genes induced during infection. Mol. Microbiol. 18: 671-683.

Cassel, D. and T. Pfeuffer. 1978. Mechanism of cholera toxin action: Covalent modification of the guanyl nucleotide binding protein of the adenylate cyclase system. Proc. Natl. Acad. Sci. 75: 2669-2673.

Centers for Disease Control and Prevention. 1996. Summary of notifiable diseases, United States, 1995. Morb. Mortal. Wkly. Rep. 44: 1-81.

Chalker, R.B. and M.J. Blaser. 1988. A review of human salmonellosis: III. Magnitude of Salmonella infection in the United States. Rev. Infect. Disease 10: 111-124.

Champion, G.A., M.N. Neely, M.A. Brennan, and V.J. DiRita. 1997. A branch of the ToxR regulatory cascade of Vibrio cholerae revealed by characterization of tox $T$ mutant strains. Mol. Microbiol. 23: 323-331.

Chang, E.B. and M.C. Rao. 1991. Intracellular mediators of intestinal electrolyte transport. In Diarrheal diseases (ed. $M$. Field), pp. 49-70. Elsevier, New York, NY.

Chen, C., N. Buchmeier, S. Libby, F. Fang, M. Krause, and D. 
Guiney. 1995. Central regulatory role for the RpoS sigma factor in expression of Salmonella dublin plasmid virulence genes. I. Bacteriol. 177: 5303-5309.

Chen, L.-M, K. Kaniga, and J. Galan. 1996. Salmonella spp. are cytotoxic for cultured macrophages. Mol. Microbiol. 21: 1101-1115.

Chiang, S., R. Taylor, M. Koomey, and J. Mekalanos. 1995. Single amino acid substitutions in the N-terminus of Vibrio cholerae TcpA affect colonization, autoagglutination, and serum resistance. Mol. Microbiol. 17: 1133-1142.

Cutrecasas, P. 1973. Gangliosides and membrane receptors for cholera toxin. Biochemistry 12: 3558-3566.

DiRita, V.J. 1992. Co-ordinate expression of virulence genes by ToxR in Vibrio cholerae. Mol. Microbiol. 6: 451-458.

- 1995. Three-component regulatory system controlling virulence in Vibrio cholerae. In Two-component signal transduction (ed. J. Hoch and T. Silhavy), pp. 351365. American Society for Microbiology, Washington, DC.

DiRita, V.J. and J. Mekalanos. 1991. Periplasmic interaction between two membrane regulatory proteins, ToxR and ToxS, results in signal transduction and transcriptional activation. Cell 64: 29-37.

DiRita, V.J., C. Parsot, G. Jander, and J. Mekalanos. 1991. Regulatory cascade controls virulence in Vibrio cholerae. Proc. Natl. Acad. Sci. 88: 5403-5407.

DiRita, V.J., M. Neely, R.K. Taylor, and P.M. Bruss. 1996. Differential expression of the ToxR regulon in classical and El Tor biotypes of Vibrio cholerae is due to biotype-specific control over toxT expression. Proc. Natl. Acad. Sci. 93: 7991-7995.

Dorman, C.J. 1991. DNA supercoiling and environmental regulation of gene expression in pathogenic bacteria. Infect. Immun. 59: 745-749.

—_. 1996. Flexible response: DNA supercoiling, transcription and bacterial adaption to environmental stress. Trends Microbiol. 4: 214-216.

Dorman, C.J., S. Chatfield, C.F. Higgins, C. Hayward, and G. Dougan. 1989. Characterization of porin and $o m p R$ mutants of a virulent strain of Salmonella typhimurium: ompR mutants are attenuated in vivo. Infect. Immun. 57: 2136-2140.

Dziejman, M. and J. Mekalanos. 1995. Two-component signal transduction and its role in the expression of bacterial virulence factors. In Two-component signal transduction (ed. J. Hoch and T. Silhavyl, pp. 305-318. American Society for Microbiology, Washington, D.C.

El-Gedaily, A., G. Paesold, C. Chen, D. Guiney, and M. Krause. 1997. Plasmid virulence gene expression induced by shortchain fatty acids in Salmonella dublin: Identification of rpoS-dependent and rpoS-independent mechanisms. J. Bacteriol. 179: 1409-1412.

Everiss, K., K. Hughes, and K. Peterson. 1994a. The accessory colonization factor and toxin-coregulated pilus gene clusters are physically linked on the Vibrio cholerae $\mathrm{O} 395$ chromosome. DNA Seq. 5: 51-55.

Everiss, K., K. Hughes, M. Kovach, and K. Peterson. 1994b. The Vibrio cholerae $a c f B$ colonization determinant encodes an inner membrane protein that is related to a family of signaltransducing proteins. Infect. Immun. 62: 3289-3298.

Field, M. 1980. Intestinal secretion and its stimulation by enterotoxins. In Cholera and related diarrheas (ed. O. Ochterlony and J. Holmgren), pp.46-52. Karger Press, Basel, Switzerland.

Fields, P.I., R.V. Swanson, C.G. Haidaris, and F. Heffron. 1986. Mutants of Salmonella typhimurium that cannot survive within macrophages are avirulent. Proc. Natl. Acad. Sci. 83: 5189-5193.
Foster, J.W. 1995. Low pH adaptation and the acid tolerance response of Salmonella typhimurium. Crit. Rev. Microbiol. 21: 215-237.

Galan, J.E. 1996. Molecular genetic bases of Salmonella entry into host cells. Mol. Microbiol. 20: 263-271.

Galan, J.E. and R. Curtiss III. 1990. Expression of Salmonella typhimurium genes required for invasion is regulated by changes in DNA supercoiling. Infect. Immun. 58: 1879-1885.

Gallegos, M.-T., C. Michán, and J.L. Ramos. 1993. The XylS/ AraC family of regulators. Nucleic Acids Res. 21: 807-810.

Garcia-del Portillo, F., J. Foster, and B. Finlay. 1993. Role of acid tolerance response genes in Salmonella typhimurium virulence. Infect. Immun. 61: 4489-4492.

Garcia Vescovi, E., F. Soncini, and E.A. Groisman. 1996. $\mathrm{Mg}^{2+}$ as an extracellular signal: Environmental regulation of Salmonella virulence. Cell 84: 165-174.

Gardel, C. and J. Mekalanos. 1996. Alterations in Vibrio cholerae motility phenotypes correlate with changes in virulence factor expression. Infect. Immun. 64: 2246-2255.

Gill, D.M. 1976. The arrangement of subunits in cholera toxin. Biochemistry 15: 1242-1248.

Gill, D.M. and R. Meren. 1978. ADP-ribosylation of membrane proteins catalysed by cholera toxin: Basis of the activation of adenylate cyclase. Proc. Nat1. Acad. Sci. 75: 3050-3054.

Goldberg, M.B., V.J. DiRita, and S.B. Calderwood. 1990. Identification of an iron-regulated virulence determinant in Vibrio cholerae, using TnphoA mutagenesis. Infect. Immun. 58: $55-60$.

Groisman, E.A. and F. Heffron. 1995. Regulation of Salmonella virulence by two-component regulatory systems. In Twocomponent signal transduction (ed. J.A. Hoch and T.J. Silhavyl, pp. 319-332. American Society for Microbiology, Washington, D.C.

Groisman, E.A. and H. Ochman. 1996. Pathogenicity islands: Bacterial evolution in quantum leaps. Cell 87: 791-794.

Groisman, E., E. Chiao, C. Lipps, and F. Heffron. 1989. Salmonella typhimurium phoP virulence gene is a transcriptional regulator. Proc. NatI. Acad. Sci. 86: 7077-7081.

Gruer, M. and J.R. Guest. 1994. Two genetically-distinct and differentially-regulated aconitases (AcnA and AcnB) in Escherichia coli. Microbiology 140: 2531-2541.

Guiney, D.G., S. Libby, F.C. Fang, M. Krause, and J. Fierer. 1995. Growth-phase regulation of plasmid virulence genes in Salmonella. Trends Microbiol. 3: 275-279.

Gulig, P.A. 1990. Virulence plasmids of Salmonella typhimurium and other Salmonellae. Microb. Pathogen. 8: 3-11.

Gulig, P., A. Caldwell, and V. Chiodo. 1992. Identification, genetic analysis and DNA sequence of a $7.8 \mathrm{-kb}$ virulence region of the Salmonella typhimurium virulence plasmid. Mol. Microbiol. 6: 1395-1411.

Hacker, J., G. Blum-Oehler, I. Muhidorfer, and H. Tschape. 1997. Pathogenicity islands of virulent bacteria: Structure, function and impact on microbial evolution. Mol. Microbiol. 23: 1089-1097.

Hall, H. and J.W. Foster. 1996. The role of fur in the acid tolerance response of Salmonella typhimurium is physiologically and genetically separable from its role in iron acquisition. $J$. Bacteriol. 178: 5683-5691.

Hanne, L.F. and R.A. Finkelstein. 1982. Characterization and distribution of the hemagglutinins produced by Vibrio cholerae. Infect. Immun. 36: 209-214.

Harkey, C.W., K.D. Everiss, and K.M. Peterson. 1994. The Vibrio cholerae toxin-coregulated-pilus gene tcpI encodes a homolog of methyl-accepting chemotaxis proteins. Infect. Immun. 62: 2669-2678. 
Heithoff, D., C. Conner, P. Hanna, S. Julio, U. Hentschel, and M. Mahan. 1997. Bacterial infection as assessed by in vivo gene expression. Proc. Natl. Acad. Sci. 94: 934-939.

Hensel, M., J. Shea, C. Gleeson, M. Jones, E. Dalton, and D. Holden. 1995. Simultaneous identification of bacterial virulence genes by negative selection. Science 269: 400-403.

Hensel, M., J. Shea, B. Raupach, D. Monack, S. Falkow, C. Gleeson, T. Kubo, and D. Holden. 1997. Functional analysis of ssal and the $s s a K / U$ operon, 13 genes encoding components of the type III secretion apparatus of Salmonella pathogenicity island 2. Mol, Microbiol. 24: 155-167.

Herrington, D., R. Hall, G. Losonsky, J. Mekalanos, R. Taylor, and M. Levine. 1988. Toxin, toxin-coregulated pili, and the tox $R$ regulon are essential for Vibrio cholerae pathogenesis in humans. J. Exp. Med. 168: 1487-1492.

Higgins, C.F., J. Hinton, C. Hulton, T. Owen-Hughes, G. Pavitt, and A. Seirafi. 1990. Protein H1: A role for chromatin sturcture in the regulation of bacterial gene expression and virulence? Mol. Microbiol. 4: 2007-2012.

Higgins, D. and V.J. DiRita. 1994. Transcriptional control of toxT, a regulatory gene in the ToxR regulon of Vibrio cholerae. Mol. Microbiol. 14: 17-29.

Higgins, D., E. Nazareno, and V.J. DiRita. 1992. The virulence gene activator from Vibrio cholerae is a member of the AraC family of transcriptional activators. I. Bacteriol. 174: 69746980.

Hirst, T., J. Sanchez, J. Kaper, S. Hardy, and J. Holmgren. 1984. Mechanism of toxin secretion by Vibrio cholerae investigated in strains harbouring plasmids that encode heat-labile enterotoxins of Escherichia coli. Proc. Natl. Acad. Sci. 81: 7752-7756.

Hoertt, B., J. Ou, D. Kopecko, L. Baron, and R. Warren. 1989. Novel virulence properties of the Salmonella typhimurium virulence-associated plasmid: Immune suppression and stimulation of splenomegaly. Plasmid 21: 48-58.

Johnston, C., D. Pegues, C. Hueck, C. Lee, and S.I. Miller. 1996. Transcriptional activation of Salmonella typhimurium invasion genes by a member of the phosphorylated responseregulator superfamily. Mol. Microbiol. 22: 715-727.

Jones, B. 1997. Host response to infection with pathogenic Salmonella. Genes \& Dev. 11: 679-687.

Jonson, G., J. Holmgren, and A.-M. Svennerholm. 1991. Identification of a mannose-binding pilus on Vibrio cholerae $\mathrm{El}$ Tor. Microb. Pathogen. 11: 433-441.

Kaper, J.B., A. Fasano, and M. Trucksis. 1994. Toxins of Vibrio cholerae. In Vibrio cholerae and cholera: Molecular to global perspectives (ed. I.K. Wachsmuth, P.A. Blake, and Ø. Olsvik), pp. 145-176. American Society for Microbiology, Washington, D.C.

Kaper, J.B., J.G. Morris, Jr., and M.M. Levine. 1995. Cholera. Clin. Microbiol. Rev. 8: 48-86.

Kaufman, M., C. Shaw, I. Jones, and R. Taylor. 1993. Biogenesis and regulation of the Vibrio cholerae toxin-coregulated pilus: Analogies to other virulence factor secretory systems. Gene 126: 43-49.

Keusch, G. and D. Thea. 1989. The Salmonellae: Typhoid fever and gastroenteritis. In Mechanisms of microbial disease (ed. M. Schaechter, G. Medoff, and D. Schlessinger|, pp. 266-275. Williams \& Wilkins, Baltimore, MD.

Kolmar, H., F. Hennecke, K. Gotze, B. Janzer, B. Vogt, F. Mayer, and H.-J. Fritz. 1995. Membrane insertion of the bacterial signal transduction protein ToxR and requirements of transcriptional activation studied by modular replacement of different protein substructures. EMBO I. 14: 3895-3904.

Kovach, M., M. Shaffer, and K. Peterson. 1996. A putative integrase gene defines the distal end of a large cluster of ToxR- regulated colonization genes in Vibrio cholerae. Microbiology 142: 2165-2174.

Knapp, S. and J. Mekalanos. 1988. Two trans-acting regulatory genes (vir and mod) control antigenic modulation in Bordutella pertussis. J. Bacteriol. 170: 5059-5066.

Lee, C.A. and S. Falkow. 1990. The ability of Salmonella to enter mammalian cells is affected by bacterial growth state. Proc. Nat1. Acad. Sci. 87: 4304-4308.

Lee, C., B. Jones, and S. Falkow. 1992. Identification of a Salmonella typhimurium invasion locus by selection for hypersensitive mutants. Proc. Natl. Acad. Sci. 89: 1847-1851.

Lee, I., J. Lin, H. Hall, B. Bearson, and J. Foster. 1995. The stationary-phase sigma factor sigma $S$ (RpoS) is required for a sustained acid tolerance response in virulent Salmonella typhimurium. Mol. Microbiol. 17: 155-167.

Levine, M., D. Nalin, J. Craig, D. Hoover, E. Bergquist, D. Waterman, H. Holley, R. Hornick, N. Pierce, and J. Libonati. 1979. Immunity to cholera in man: Relative role of antibacterial versus antitoxic immunity. Trans. R. Soc. Top. Med. Hyg. 73: 3-9.

Levine, M., J. Kaper, D. Herrington, G. Losonsky, J. Morris, M. Clements, R. Black, B. Tall, and R. Hall. 1988. Volunteer studies of deletion mutants of Vibrio cholerae O1 prepared by recombinant techniques. Infect. Immun. 56: 161-167.

Lindgren, S., I. Stojilikovic, and F. Heffron. 1996. Macrophage killing is an essential virulence mechanism of Salmonella typhimurium. Proc. Natl. Acad. Sci. 93: 4197-4201.

Litwin, C.M. and S.B. Calderwood. 1994. Analysis of the complexity of gene regulation by Fur in Vibrio cholerae. J. Bacteriol. 176: $240-248$.

Lockman, H.A., J.E. Galen, and J.B. Kaper. 1984. Vibrio cholerae enterotoxin genes: Nucleotide sequence analysis of DNA encoding ADP-ribosyltransferase. I. Bacteriol. 159: 1086-1089.

Lospalluto, J.J. and R.A. Finkelstein. 1972. Chemical and physical properties of cholera exo-enterotoxin (choleragen) and its spontaneously formed toxoid (choleragenoid). Biochim. Biophys. Acta 257: 158-166.

Mahan, M.J., I.M. Slauch, and J. Mekalanos. 1993. Selection of bacterial virulence genes that are specifically induced in host tissues. Science 259: 686-688.

Maloy, S., V. Stewart, and R. Taylor. 1996. Genetic analysis of pathogenic bacteria: A laboratory manual. Cold Spring Harbor Laboratory Press, Cold Spring Harbor, NY.

Maurelli, A. and P. Sansonetti. 1988. Identification of a chromosomal gene controlling temperature-regulated expression of Shigella virulence. Proc. Natl. Acad. Sci. 85: 2820-2824.

Mekalanos, J. 1992. Environmental signals controlling expression of virulence determinants in bacteria. I. Bacteriol. 174: $1-7$.

Mekalanos, J. and J. Sadoff. 1994. Cholera vaccines: Fighting an ancient scourge. Science 265: 1387-1389.

Mekalanos, J, R.J. Collier, and W.R. Romig. 1979. Enzymatic activity of cholera toxin. II. Relationships to proteolytic processing, disulfide bond reduction, and subunit composition. J. Biol. Chem. 254: 5855-5861.

Mekalanos, J., D. Swartz, G. Pearson, N. Harford, F. Groyne, and M. deWilde. 1983. Cholera toxin genes: Nucleotide sequence, deletion analysis, and vaccine development. Nature 306: 551-557.

Miller, J.F., J. Mekalanos, and S. Falkow. 1989. Coordinate regulation and sensory transduction in the control of bacterial virulence. Science 243: 916-922.

Miller, S.I. and J. Mekalanos. 1990. Constitutive expression of the PhoP regulon attenuates Salmonella virulence and survival within macrophages. I. Bacteriol. 172: 2485-2490.

Miller, S.I, A.M. Kukral, and J. Mekalanos. 1989. A two-compo- 
nent regulatory system ( $p h o P$ phoQ) controls Salmonella typhimurium virulence. Proc. Natl. Acad. Sci. 86: 5054-5058.

Miller, S.I., E. Hohmann, and D. Pegues. 1995. Salmonella (including Salmonella typhi). In Principles and practice of infectious diseases (ed. G. Mandell, J. Bennett, and R. Dolin), pp. 2013-2033. Churchill Livingstone, New York, NY.

Miller, V.L. and J. Mekalanos. 1984. Synthesis of cholera toxin is positively regulated at the transcriptional level by toxR. Proc. Natl. Acad. Sci. 81: 3471-3475.

Miller, V.L., R.K. Taylor, and J. Mekalanos. 1987. Cholera toxin transcriptional activator ToxR is a transmembrane DNA binding protein. Cell 48: 271-279.

Monack, D., B. Raupach, A. Hromockyi, and S. Falkow. 1996. Salmonella typhimurium invasion induces apoptosis in infected macrophages. Proc. Natl. Acad. Sci. 93: 98339838.

Muffler, A., D. Fischer, S. Altuvia, G. Storz, and R. HenggeAronis. 1996. The response regulator RssB controls stability of the $\sigma^{5}$ subunit of RNA polymerase in Escherichia coli. EMBO I. 15: 1333-1339.

O'Byrne, C. and C. Dorman. 1994. The spv virulence operon of Salmonella typhimurium LT2 is regulated negatively by the cyclic AMP(cAMP)-cAMP receptor protein system. J. Bacteriol. 176: 905-912.

Ogierman, M.A. and P.A. Manning. 1992. Homology of TcpN, a putative regulatory protein of Vibrio cholerae, to the AraC family of transcriptional regulators. Gene 116: 93-97.

Osek, J., G. Jonson, A.-M. Svennerholm, and J. Holmgren. 1994. Role of antibodies against biotype-specific Vibrio cholerae pili in protection against experimental classical and El Tor cholera. Infect. Immun. 62: 2901-2907.

Ottemann, K. and J. Mekalanos. 1996. The ToxR protein of Vibrio cholerae forms homodimers and heterodimers. I. Bacteriol. 178: 156-162.

Parkinson, S. 1995. Genetic approaches for signaling pathways and proteins. In Two-component signal transduction (ed. J. Hoch and T. Silhavyl, pp.9-23. American Society for Microbiology, Washington, D.C.

Parsot, C. and J.J. Mekalanos. 1990. Expression of ToxR, the transcriptional activator of the virulence factors in Vibrio cholerae, is modulated by the heat shock response. Proc. Natl. Acad. Sci. 87: 9898-9902.

- 1992. Structural analysis of the acfA and acfD genes of Vibrio cholerae: Effects of DNA topology and transcriptional activators on expression. J. Bacteriol. 174: 5211-5218.

Peterson, K. and J. Mekalanos. 1988. Characterization of the Vibrio cholerae ToxR regulon: Identification of novel genes involved in intestinal colonization. Infect. Immun. 56: 2822-2829.

Pratt, L.A. and T.J. Silhavy. 1996. The response regulator SprE controls the stability of RpoS. Proc. Nat1. Acad. Sci. 93: 2488-2492.

Rhine, J.A. and R.K. Taylor. 1994. TcpA pilin sequences and colonization requirements for $\mathrm{Ol}$ and $\mathrm{O} 139$ Vibrio cholerae. Mol. Microbiol. 13: 1013-1020.

Richardson, K. 1991. Roles of motility and flagellar structure in pathogenicitiy of Vibrio cholerae: Analysis of motility mutants in three animal models. Infect. Immun. 59: 2727-2736.

Riesenberg-Wilmes, M., B. Bearson, J. Foster, and R. Curtis III. 1996. Role of the acid tolerance response in virulence of Salmonella typhimurium. Infect. Immun. 64: 1085-1092.

Shea, J., M. Hensel, C. Gleeson, and D. Holden. 1996. Identification of a virulence locus encoding a second type III secretion system in Salmonella typhimurium. Proc. Natl. Acad. Sci. 93: 2593-2597.

Skorupski, K. and R.K. Taylor. 1997. Cyclic AMP and its recep- tor protein negatively regulate the coordinate expression of cholera toxin and toxin-coregulated pilus of Vibrio cholerae. Proc. Nat1. Acad. Sci. 94: 265-270.

Slauch, J.M. and T.J. Silhavy. 1996. The porin regulon: A paradigm for the two-component regulatory systems. In Regulation of gene expression in Escherichia coli led. E.C.C. Lin and A.S. Lynch), pp. 383-417. R.G. Landes Co., Austin, TX.

Stocker, B.A.D. 1993. Attenuation of Salmonella by auxotrophy. In Biology of Salmonella (ed. F. Cabello, C. Hormaeche, P. Mastroeni, and L. Bonima), pp.309-322. Plenum Press, New York, NY.

Stoebner, J.A. and S.M. Payne. 1988. Iron-regulated hemolysin production and utilization of heme and hemoglobin by Vibrio cholerae. Infect. Immun. 56: 2891-2895.

Strom, M. and S. Lory. 1993. Structure-function and biogenesis of the type IV pili. Annu. Rev. Microbiol. 47: 567-596.

Taylor, R.K., V.L. Miller, D. Furlong, and J. Mekalanos. 1987. Use of $p h o A$ gene fusions to identify a pilus colonization factor coordinately regulated with cholera toxin. Proc. Natl. Acad. Sci. 84: 2833-2837.

Thelin, K. and R.K. Taylor. 1996. Toxin-coregulated pilus, but not mannose-sensitive hemagglutinin, is required for colonization by Vibrio cholerae O1 El Tor biotype and O139 strains. Infect. Immun. 64: 2853-2856.

Thomas, S., S. Williams, and P. Manning. 1995. Regulation of tcp genes in classical and El Tor strains of Vibrio cholerae O1. Gene 166: 43-48.

Valdivia, R. and S. Falkow. 1996. Bacterial genetics by flow cytometry: Rapid isolation of Salmonella typhimurium acid-inducible promoters by differential fluorescence induction. Mol. Microbiol. 22: 367-378.

Valone, S.E., G.K. Chikami, and V.L. Miller. 1993. Stress induction of the virulence proteins (SpvA, $-\mathrm{B}$, and $-\mathrm{C}$ ) from native plasmid pSDL2 of Salmonella dublin. Infect. Immun. 61: 705-713.

Wachsmuth, I.K., Ø. Olsvik, G.M. Evins, and T. Popovic. 1994. Molecular epidemiology of cholera. In Vibrio cholerae and cholera: Molecular to global perspectives (ed. I.K. Wachsmuth, P.A. Blake, and Ø. Olsvik), pp. 357-370. American Society for Microbiology, Washington, D.C.

Waldor, M.K. and J.J. Mekalanos. 1996. Lysogenic conversion by a filamentous phage encoding cholera toxin. Science 272: 1910-1914.

Williams, S.G., S.R. Attridge, and P.A. Manning. 1993. The transcriptional activator HlyU of Vibrio cholerae: Nucleotide sequence and role in virulence gene expression. Mol. Microbiol. 9: 751-760. 


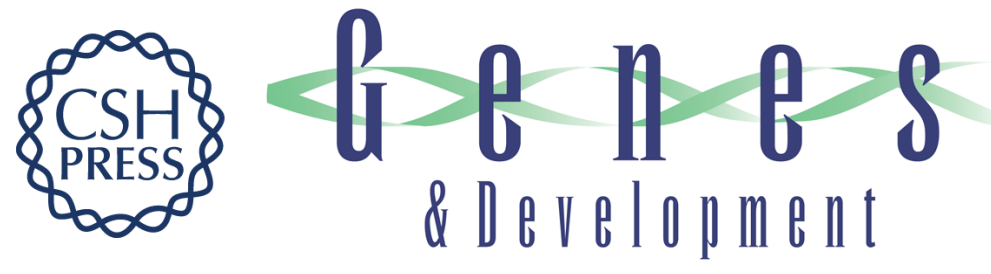

\section{Survival in a cruel world: how Vibrio cholerae and Salmonella respond to an unwilling host.}

J Slauch, R Taylor and S Maloy

Genes Dev. 1997, 11:

Access the most recent version at doi:10.1101/gad.11.14.1761

References This article cites 110 articles, 64 of which can be accessed free at:

http://genesdev.cshlp.org/content/11/14/1761.full.html\#ref-list-1

License

Email Alerting

Service right corner of the article or click here.

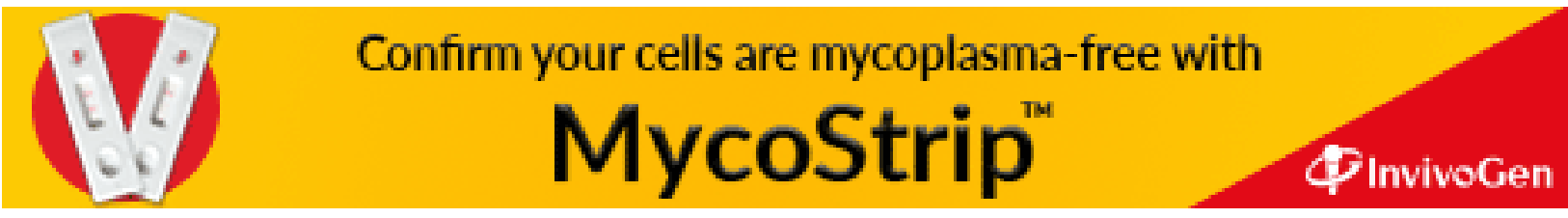

